\title{
The Challenges Faced by Preschool Children with Mental Disabilities in Their School Integration. Views of Preschool Teachers
}

\author{
Theano Kalpidi \\ National Kapodistrian University of Athens, Athens, Greece \\ Email: tkalpidi@gmail.gr
}

How to cite this paper: Kalpidi, T. (2021) The Challenges Faced by Preschool Children with Mental Disabilities in Their School Integration. Views of Preschool Teachers. Open Access Library Journal, 8: e7675. https://doi.org/10.4236/oalib.1107675

Received: June 22, 2021

Accepted: August 1, 2021

Published: August 4, 2021

Copyright $\odot 2021$ by author(s) and Open Access Library Inc.

This work is licensed under the Creative Commons Attribution International License (CC BY 4.0).

http://creativecommons.org/licenses/by/4.0/

\section{(c) (i) Open Access}

\begin{abstract}
In the present study, the aim was to explore the views of preschool teachers in relation to the challenges faced by children with intellectual disabilities in their school integration. To achieve this, four research questions were prepared and a quantitative survey was conducted through a questionnaire. Initially, the theoretical framework of Mental Disability and Integration was presented, on which the whole subsequent study was based. Subsequently, research related to the subject was reviewed and data were identified for further investigation. The whole research process followed the design of the educational quantitative research, where the issues of ethics, as well as those of validity and reliability, were ensured. This was followed by an analysis of the collected data, with the Spss program as well as their detailed presentation. The research questions were then discussed in relation to whether they were answered by the research process and in relation to the theoretical background. Finally, the research difficulties and the proposals for further research are presented.
\end{abstract}

\section{Subject Areas}

Special Education

\section{Keywords}

Mental Disabilities, Integration, Preschool Children, Intellectual Disabilities

\section{Introduction}

Today's society has made significant progress compared to some decades ago, in terms of prejudices against people with some form of disability, whether physical 
or mental. Over the past years, there have been institutional changes regarding the naming of people with special educational needs as well as people with disabilities. More specifically, mental disability as a term appears in the DSM-V and has been used in the literature in recent years, replacing the term mental retardation. Clearly such a shift in social perception could not leave the education industry unaffected. Because social perceptions are first formed at school age and then consolidated, a fact that demonstrates the importance of all the elements that determine school education.

This change in the perceptions of educators and society in general has led to the need to recognize the inalienable right of every individual and more specifically of every child to accept, equal participation in the learning process and to provide equal opportunities for learning, regardless of physical condition. or mental well-being of the child [1]. The above condition was the starting point for the interdisciplinary cooperation of teachers of general education and special education and the finding and elaboration of cooperative practices to achieve the desired result and the optimization of the dynamics of each school class. This process aims at the integration of the child with mental disability in the general class.

The main goal of integration is not a school that will co-exist and coexist with students with special educational needs or not, but a school in which it will be possible to co-educate with respect to their personal learning and social needs both students with and without disabilities. The main role for successful integration is played by the teachers and the techniques they use. Especially in preschool education, where the role of the educator is in charge of providing the child with opportunities, stimuli and materials for his comprehensive development, it makes even more serious his participation in the development of the child with mental disability. In the accession process, children are likely to face significant challenges until the situation normalizes. The teacher from his position is called to do what is humanly possible in order to smooth over any difficulties and to help the child to meet the challenges that arise.

As mentioned above, in childhood the individual's perceptions of society are formed and in later school life are consolidated. It is therefore very important to explore the views of preschool teachers on the challenges faced by children with disabilities in school [2].

Despite the key role of the pre-school teacher in the inclusive education of the child with disabilities and the normalization of possible challenges, a gap is found in the Greek literature regarding the review of the views of these teachers. Thus, the purpose of this research is to explore the views of preschool teachers regarding the challenges faced by a child with intellectual disabilities in their school integration. More specifically, the factors that affect the effectiveness of daily activities aimed at creating an inclusive climate in the preschool class will be investigated. The concerns of kindergarten teachers as well as the conditions related to the implementation of inclusive education will also be investigated. 


\section{Theoretical Framework}

\subsection{Terms and Definition: Mental Disability}

Defining the concept of mental disability accurately and with absolute clarity has been a major challenge for the scientific community from the outset. The definitions given over the years reflect the perception of society at the moment about mental disability [3]. Mental disability (NA) is difficult to define universally because in each case it is portrayed differently and different aspects and manifestations of the phenomenon are manifested. From time to time there have been several interdisciplinary attempts to define mental disability but each scientist delimited the definition based on his own special knowledge [4].

More specifically, with a brief review of the literature, various terms are encountered to describe mental disability. Terms such as privacy, insanity, oligophrenia, cretinism, mental retardation, mental disability and many more. The most common and the most common is the term mental retardation which has been used in the Greek translation of the diagnostic manuals DSM-IV and ICD10 [5]. However, the term mental retardation promotes disability as a defect of the individual himself. In contrast, the term mental disability considers disability as a combination of the capabilities of the person with a disability and the environment in which he or she is called to act [6].

According to the DSM-V \& DSM-TR [7] as mentally retarded is defined the person whose a) his general mental ability is below average (the IQ based on psychometric intelligence tests should be below 70), b) the mental retardation has manifested during the developmental period and before the end of the eighteenth year of age and c) presents deficiencies in its adaptive behavior. For example, in the fields of communication, self-care, etc. According to the American Association for the mental and developmental disabilities [8] cognitive disability characterized by significant limitations both in intellectual functioning and in adaptive behavior, which covers mental, social and practical skills.

In order for this definition to be valid, however, it has some basic conditions. The five principles that validate the above definition are the following. Initially the limitations that appear in the individual's functionality must be evaluated within the limits of his social environment, which is common for the individual's age group and culture. Also, in order to achieve the validity of the evaluation, linguistic and social differences, communication as well as sensory and motor factors must be taken into account. The limitations encountered by the person with a disability exist in parallel with possibilities. It is also a given that the description of the limitations that appear in the functionality of a person with a disability, is done in order to create a system of services that will meet the needs of the person. Finally, with the appropriate individual support for his needs, the functionality of the individual will improve for a certain period of time [9]. In addition, the mental retardation must have occurred to the individual for the first time before the age of eighteen [10]. 


\subsection{Diagnostic Criteria}

The scientific community relies on two textbooks to diagnose mental disability. The DSM-V of the American Psychiatric Association and the ICD-10 of the World Health Organization (WHO). The criteria for defining the MD are based on two axes. First it concerns the mental limitations that the person displays. Secondly, it refers to the discounts that the person shows regarding the adaptive behavior. Mental retardation can be controlled either through the clinical evaluation process or through weighted intelligence measurement tools such as the WISC [11].

According to the American Psychiatric Association, the conditions for diagnosing a person with $\mathrm{MD}$ are the following. Initially, this person should have a reduction in their general mental abilities, such as reasoning, programming, problem solving, critical thinking as well as experiential and academic learning. In addition, he should show a significant reduction in his general mental abilities in relation to the age and social group in which he belongs in the following areas. That is, in relation to the ability to communicate, the ability to socialize, the functionality within the school or work environment as well as the personal independence of the individual [7].

At the same time, according to the diagnostic manual of the WHO, the conditions for diagnosing a person with mental disability are the following. The person should show retardation or imperfect mental development which is characterized by obvious disturbances in his skills during the developmental period. Which concern the overall level of intelligence of the individual and affect the cognitive, linguistic, motor and social skills (WHO 2016). In addition, the World Health Organization notes that mental retardation can occur without any other physical or mental disorder. However, he points out that people with mental disabilities are three to four times more likely to develop comorbidity with a variety of mental disorders than the general population. He also notes that people with mental disabilities are always affected by adaptive behavior. In addition, the World Health Organization points out that people with intellectual disabilities are often at risk of being exploited (WHO 2016).

\subsection{Classification of Mental Disability}

The WHO proposes the following classification for mental disability in its ICD-10 diagnostic manual, taking into account the degree of intelligence (IQ) and the general behavior of the individual in relation to the areas described above.

Mild Mental Disability

People with mild mental disabilities have an IQ of 50 - 55 to 70 . They are the most populous group of people with intellectual disabilities at $85 \%$. The causes of the appearance of light SE are mainly organic and perinatal. Generally, people with mild SE present a delay in their perceptual abilities. Their communication is satisfactory as they have the ability to express themselves verbally (WHO 
2016). They always show a delay in the appearance of speech. They can also be independent and self-sufficient. In terms of the school and work difficulties they face, the first part concerns the writing and reading skills while the second the theoretical skills. In addition, they face emotional and social difficulties [6].

Moderate Mental Disability

Moderate mental disability affects $10 \%$ of all people with mental disabilities. People in this category have an IQ of 35 - 40 to 50 - 55. The causes of moderate mental disability are mainly organic endocrinological or metabolic in nature. Co-morbidity with epilepsy and various neurological and physical disabilities is often monitored. People with moderate mental retardation show a slow development of comprehension and speech production and therefore have difficulty in verbal communication. They have school difficulties. They often have reduced self-efficacy which is exacerbated by the problems they face in both their gross and fine mobility. In infancy they have a significant delay in conquering developmental milestones by developmental stage. While as adults in a well-framed work environment they can perform simple practical tasks. Recognition of moderate mental disability occurs in infancy and early childhood [12].

Severe Mental Disability

People with severe mental disabilities make up 3\% - 4\% of the total population of people with disabilities. Their IQ is from 20 - 25 to 35 - 40. The causes of severe mental disability are mostly due to infections, toxins or CNS damage that occur prenatally, perinatally and postnatally. People with severe mental disabilities have major cognitive deficits and motor disorders. In contrast to the above categories here people need support for their daily routines.

Severe Mental Disability

Severe mental disability occurs in $1 \%-2 \%$ of the total population with mental disability. These people have an IQ below 20 to 25 . The causes of severe mental disability are mainly organic and often other neurological or physical disabilities are observed at the same time. Concomitant disorders such as diffuse developmental disorder often occur. In these individuals there is a greater risk of developing psychopathology. Very large deficits occur both in the cognitive and in the motor and communication sector since there is no verbal communication. These people show reduced self-care due to the sensory-motor difficulties they face. There is room for improvement if these people join in intervention programs (WHO, 2016).

\section{Unspecified Mental Disability}

This category includes people who are suspected of having a mental disability but at the same time are unable to be assessed with weighted psychometric tests due to disability. The younger the person who needs diagnosis, the more difficult the evaluation process [7].

\subsection{Self-Care in People with Intellectual Disabilities}

According to Aldridge (2010), achieving and preserving the independence of 
people with intellectual disabilities is of major importance. It is an indisputable fact that the part of self-care and management of daily challenges is a very important part for the socialization of the child with disabilities [13]. Based on the literature, the need to learn skills of self-care and management of daily challenges arises directly in people with mental or other forms of disability. Because through learning, functionality increases in terms of daily activities [13]. On the contrary, people with mental disabilities present significant difficulties in terms of self-care, as a result of which they lag behind growing up in their social development [13].

At this point, the education of people with intellectual disabilities needs to be emphasized. If the education is systematic from an early age and is organized and individualized with practices and programs aimed at self-care of the person with a disability, in adulthood the person with a disability may be self-sufficient and do not need support for the functions of daily life [13].

\subsection{Characteristics of Children with Mental Disabilities}

According to Polychronopoulou [4] children with mental disabilities are a heterogeneous group with differences in their IQ. However, they do have some commonalities related to cognitive characteristics, physical and motor skills, emotional characteristics and behavioral problems and lack of interest in learning. In terms of cognitive characteristics, children with $\mathrm{AD}$ develop in $1 / 2$ or $1 / 3$ of children at the rate of typical developmental children. They have reduced learning ability because they show inability to concentrate and problems in their short-term memory, the proper functioning of which is a key learning factor. In addition, they face communication problems because they have imperfect language development and language deficiencies that hinder both the cognitive and the social sector.

In terms of physical and motor abilities, there are difficulties here as well. Although children with intellectual disabilities usually do not differ in height and weight from the age group to which they belong, they nevertheless show a slowdown in mobility development compared to developmental milestones. There are usually neurological problems that lead to deficits in motor skills as well as sensory problems of vision or hearing.

In addition to the emotional characteristics and behavioral problems of children with mental disabilities, Polychronopoulou [4] mentions the following. These children have great difficulty adapting to different environments. They are also more vulnerable to mental disorders than the general population. They often show elements of erratic behavior because they are unable to distinguish good from evil and therefore do not realize the consequences of their actions. Emotional instability is often observed and in cases of children with high stress impulsivity is detected. In cases where the child has a mild mental disability, this low appreciation and impulsivity are usually the result of a low socio-economic environment. On the contrary, in cases where the child has a severe mental disa- 
bility, the above is a result of the low IQ.

Finally, in terms of lack of interest in learning, children with intellectual disabilities show a reluctance to deal with demanding issues because the failures they experienced in early childhood had a negative impact on their interest in learning. Thus they tend to avoid difficult and demanding situations while at the same time showing an apathy for what is happening in their environment. Often when faced with a demanding situation they react aggressively because they perceive it as a threat.

\subsection{Epidemiological Data and Causes of Mental Disability}

The causes of Mental Disability are divided into genetic and environmental. Although in $30 \%-40 \%$ of cases they are unknown. With respect to genetic causes concern mainly hereditary factors, chromosomal abnormalities and metabolic abnormalities [4]. In addition to environmental causes according to Kakouros \& Maniadakis [5], they can affect at any time after conception either during pregnancy or during childbirth or even in childhood.

Mental disability is recorded in $1 \%-3 \%$ of the general population. It is pointed out that it does not appear with equal distribution in all age groups, in gender and in the social stratum. $44 \%$ to $50 \%$ of cases with mental disability are found in family contexts with low social, economic and educational level. It is alleged that this is because in these cases there is a lack of information about the needs of prenatal care for the mother and attention from her [14]. According to a multi-year research conducted from 1997 to 2008, the incidence of mental disability in boys is around $0.78 \%$ while in girls it is at 0.63 [15]. That is 1.5 for boys to 1 for girls. It is possible that because boys have higher rates of prematurity in childbirth, they become more vulnerable than girls to congenital disorders or external factors that threaten the CNS.

\subsection{Institutional Framework}

Internationally, the rights of persons with disabilities are legally enshrined in the Convention on the Rights of Persons with Disabilities, as well as through the Optional Protocol that accompanies it (United Nations, 2006).

The period after the Metapolitism was the one during which the Greek society tried to follow the international developments. It therefore notes the shift of interest worldwide, to people with disabilities by adopting and implementing policies, methods and practices for special education and training and proceeds to corresponding legislation from the second half of the 1970s [16].

The CRPD was formally established in 2006 and was officially ratified by the UN. Greece proceeded to ratify it six years later with law number 4074/2012 [17]. According to the CRPD, the dignity of the individual, his autonomy, his independence, his free will as well as his freedom to choose for himself should be respected. Another important principle of the contract is that of non-discrimination. It also provides for active participation and integration into society as well as re- 
spect for difference and acceptance of people with disabilities as part of human nature and humanity. Equal opportunities, accessibility, equality between men and women as well as respect for the evolving abilities of children with disabilities to maintain their identity are promoted [17]. Article 7 of prefecture $4074 / 2012$ provides for the right to full enjoyment of all their rights and freedoms, on an equal basis with other children. Article 8 safeguards that Member States will implement appropriate practices to awaken society about people with disabilities and to cultivate a culture of respect for and disability for people with disabilities. Articles 17 and 19 guarantee the physical and mental autonomy of people with disabilities, as well as their independent integration into society. In addition, Article 24 guarantees the right of persons with disabilities to education. By ensuring an inclusive education system at all levels as well as lifelong learning. Which is the way in which people with disabilities will be able to participate actively and on an equal footing with the rest of the community, and the area where diversity will be perceived as part of the individual, respected and not perceived as an obstacle [18].

Students with disabilities and special educational needs include, among others, students with sensory visual and hearing disabilities, motor disabilities and mental disabilities. Where the objectives of Special education and training for the above is the timely diagnosis and assessment of special educational needs in the competent bodies. The systematic intervention in preschool age and the individualization of both the educational program and the supervisory material and equipment for the purpose of rehabilitation.

\subsection{Theoretical framework: Integration}

\subsubsection{Definition: Conceptual Approach}

The changes that took place in the social perceptions regarding the possibilities of the disabled led to the need for reprogramming of the educational policy of the country but also internationally. The school and social inclusion of children with special educational needs has been at the heart of European education policy in recent years. The integration aims at transforming the school structures into a school suitable for all students in which equal opportunities in learning will be provided to both children with special educational needs and non-children.

Integration is defined as "the systematic placement of one within something else and the completion of the subject as an independent, whole part of a larger whole" [19]. That is, the essential integration of the child in social groups of peers, his smooth participation in the learning experience and process and his absolute acceptance by classmates and educational staff.

\subsubsection{School Integration}

Various components affect the school integration of a child with special educational needs. $\mathrm{T}$ the teaching staff and between the labor relations is an important 
influence factor. In addition, the adequacy of educational support systems for both teachers and students play a key role in the child's school integration. Another very important factor is the cooperation of general and special education teaching staff for the smooth and successful integration of the child with special educational needs [20].

In the past, integration was not of major importance to the educational community. During the 20th century, changing social attitudes to the scientific community so changes in a variety of disciplines including education leading to the integration of disabled people into society in general and by extension school. It is noteworthy that in the literature there is often confusion between the term inclusion and the term integration. Both terms have in common that they concern the coexistence of children with special educational needs and not in the same educational context. Specifically, the integration focuses on the fact that the member retains his characteristics within the group. Therefore, it is understood that the modern educational policy embraces and embraces the principles of co-education of children with special educational needs and not [21].

\subsection{Models for Disability}

\subsubsection{Medical Model}

The medical model for disability is ahead of time and considers that any dysfunction of the body is due to specific causes that must be detected by clinical findings. He does not accept that health, apart from the biological, is also a social phenomenon and depends on the natural environment of the individual, failing to interpret the different recovery time of patients with the same disease, psychosomatic phenomena, embodied pains. With regard to disability, the medical model does not take into account the effects of the social environment, while disability is perceived as a personal problem of the sufferer. At the same time, disability is considered a condition that needs treatment and any intervention occurs on this basis. In the medical model, the evaluation is done through strictly defined criteria of a quantitative nature [22].

\subsubsection{Social Model}

In contrast to medicine, the social model now perceives the individual as a biological, psychological and social being and considers health to be an overall state of equilibrium between these manifestations and calls on treating physicians to understand the multidimensional nature of individual health. In relation to disability, this model argues that disability is socially framed. In contrast to the medical model, here the emphasis is on the person-environment relationship and how the environment will be adapted to the needs of the person with a disability and not the other way around. It also emphasizes that there is a collective responsibility in society for the oppression of a person with a disability. While here the intervention has the meaning of strengthening the child's potential and not the treatment [22]. 


\section{A Survey Review}

\subsection{Inclusion of Children with Special Educational Needs in Pre-School Education}

In Anastasiou [23] research on the inclusion of children with special educational needs in preschool education, a case study was conducted on a student with special educational needs. The research was carried out in Volos in a preschool unit and lasted two weeks. The research findings are as follows.

From the observation of the researcher it results that in the case of children with special educational needs the integration is achieved either in the regular department with parallel support, or in the special department with a special teacher. It seems that special and general school operate in parallel. From the observation made by the researcher, she found that the educators consider the kindergarten a "suitable ground" for the implementation of integration practices. There was also a difference between the special educator and the other educators in terms of the frequency of inclusion practices. There are also multiple benefits to the inclusion of students with special educational needs in the general school on both sides in the areas of socialization, the development of friendships and acceptance of diversity. The same benefit benefits the child who was observed.

\subsubsection{School Inclusion of Children with Intellectual Disabilities in the General Class}

In a study by Kaidanzi on the school inclusion of children with mental retardation, the general class held in Thessaloniki for 5 primary school teachers observed the following. As for a portion of teachers, it seems that they focus on the learning part, ignoring the social part, either because they are unable to work it without the cooperation of colleagues or because they consider that it does not fall within their responsibilities, while identifying difficulties in children's social relationships. Therefore, there is a distancing in matters of social inclusion. It is observed that the responsibility for this is attributed to the child himself or to his family. In addition, the lack of cooperative spirit by colleagues is considered a given, with the result that any individual intervention is considered in vain. As a result, there is an attachment to the curriculum and a passive attitude of the teacher. In addition, teachers seem to have low self-esteem in relation to the challenges they face.

On the contrary, the other participating teachers seem to adopt a more dynamic and energetic attitude. It is noted that the specific teachers perceive as part of their work both the learning and the social part as they use a clear goal setting and framework of rules to achieve the desired result. Among other goals, teachers aim to strengthen self-esteem, to develop social skills. A characteristic of the second group of teachers is that they consider it important to work with colleagues and the family so that there is a consequence. They consider it very important to build a relationship of trust with the child in order to make the most of their cooperation. It seems that they utilize activities beyond the curri- 
culum to enhance the skills of the child. Finally, they typically state that continuing education is important.

At the same time, in a study by Boteli on the social inclusion of kindergarten children with mental disabilities, which involved forty preschool children with mild mental disabilities, the researcher had the following findings. Regarding the social integration of children, the effort to provide equal opportunities and environment as well as a climate of acceptance seems to be more developed in combination with the strengthening of positive emotions in children. The creation of opportunities for social interaction is less developed. At moderate levels and slightly above is found the participation of children with intellectual disabilities in group activities that do not concern the learning part but the company on a friendly level. It is noted that children find it difficult to manage negative reactions from peers and therefore avoid group activities given that corresponds to the mental limitations that children with mental disabilities have. Regarding the participation in group activities and the company on a friendly level, there are no big differences with the rest of the student population because due to the young age they do not seem to have much differences in their interpersonal relationships and in the game. In conclusion, it seems that children with intellectual disabilities do not face particular challenges regarding their social integration within the school context or if they face some difficulties it is not to such an extent that it leads to social isolation.

\subsubsection{Views of Pre-School Teachers on the Inclusion of Children with Special Educational Needs}

Two hundred primary school teachers participated in a subsequent study by Tsiomi which investigates the views of preschool teachers on the inclusion of children with special educational needs. The research lasted one month and the teachers were given open questionnaires. The research shows the following.

Teachers would not be particularly anxious if they had a mentally retarded student in charge. More anxiety is noted in women kindergarten teachers at the idea of the presence of a child with mental retardation in their classroom. At the same time, kindergarten teachers appear to frequently apply all integration practices, thus contributing to the implementation of the institution of integration in the general school. They also look positive in their cooperation with other teachers, professionals and parents. They seem empowered to effectively manage annoying behavior in the classroom. There was a difference between those who have a doctorate in special education and those who do not have access to internship practices.

Participants believe that they will not be able to help all students equally if they have a child with special educational needs in the classroom. In addition, the latter are concerned that they are not properly trained to teach a child with special educational needs. Teachers seem to be in a sample, generally accepting people with disabilities and not "underestimating" their interactions with these people. 
Finally, teachers are calling for changes to better integrate children with special educational needs. The changes that are requested are: changes that concern the school environment, changes that concern the education and training of teachers, changes that concern any kind of help that teachers ask for, changes that concern the curriculum and changes that concern the parents of students.

\subsubsection{Social Support for Students with Intellectual Disabilities in the School Context}

A recent study by Argyriou examining teachers' views on social support for children with mild intellectual disabilities in primary education involved twenty general and special education primary school teachers. The research was carried out in the prefecture of Thessaloniki. The main findings of the research are the following. The primary issue that arises is the factor of teachers' demographics does not show any particular difference, in terms of the social support they provide to students with intellectual disabilities. It is then found that all participants are aware of the importance of the terms social support and social network and acknowledge the importance they have within the educational context. At the same time, however, they note the difficulty in developing an appropriate pedagogical program.

In addition, it is noted that they adopt positive effective techniques in relation to the axes of self-service and the achievement of learning goals since they include students in learning through imitation of models while gradually withdrawing. Based on their answers, it seems that all the teachers make efforts to provide their students with the positive support they need, building a relationship of trust so that the children can turn to them to find a common solution to the problems that arise without themselves. to substitute the child in his choices. Finally, it is presented that the largest part of the participants provides their students with the appropriate in each case based on the theory, practical and emotional social support to students with mild and moderate mental disability in general school.

\section{Ethical Issues and Research Methodology}

\subsection{Educational Research}

According to Cohen et Manion [24], educational research has a dual nature. In particular, the term educational research describes the systematic investigation with a defined way of thinking but also the activity of educational research itself. The main goal of educational research is to embellish the already existing knowledge in the specific scientific field under study as well as the emergence of innovative elements. This can be achieved by presenting new findings, updating past ones, exploring validity data and introducing new practices [24].

Through the data resulting from educational research, the new practices applied in the educational sector are delimited. At the same time, the existing knowledge in the wider field of education sciences is expanded [24]. Therefore, it 
is understood that the present investigation is part of the educational ballast with defense because updates oldest scientific data and findings through the resulting new innovative data covering bibliographical gaps.

\subsection{Research Approach}

In the present research the research approach used was the descriptive-exploratory. The aim of the given research approach is to record the aspects of a phenomenon and to highlight and correlate the general trends. In addition, the investigation of correlations between variables and research topic is an element that characterizes this approach.

\subsection{Research Tool}

The most appropriate way to collect data in a quantitative survey is the questionnaire [25]. For the investigation and measurement of trends there are various methodological approaches to the design of scales, the best known of which are the Likert, Guttman and Turstone scales. For this reason, questionnaires will be provided for the conduct of the present survey, which in its research tool uses the Likert scale because it is simpler in its preparation and is often preferred in social research. The Likert scale aims to measure the attitudes or views of participants, who can choose one of the existing fixed-form responses. The set of questions posed represents the research question. The answers available express whether the participant agrees or disagrees with the statement-question.

In the present research, a questionnaire was used, which has been drawn from the literature [26] and has been tested for reliability, having a high Cronbach reliability index of $=0.876$. The questionnaire includes Likert ordinal scales (33 questions), which are divided into three sections. The first section (18 questions), concerns the factors that affect the effectiveness of daily activities aimed at creating an inclusive climate in the preschool classroom. Section B (5 questions) deals with the concerns of kindergarten teachers regarding the integration and Section C (10 questions) concerns the conditions for the implementation of the integration in the kindergarten.

All personal data collected by the researcher (questionnaires) will be used solely for the purpose of conducting the research and will not be disclosed to third parties without our prior consent.

\subsection{Sampling}

The main goal of any sample survey is the representativeness of the population in which it is carried out. It is therefore desirable and necessary that the demographic and social characteristics of the participants represent the general population concerned by the survey. Whether the sample is representative also determines the possibility of generalizing the research findings [27].

In the present research the type of sampling is without chances and more specifically the convenient sampling will be applied. Convenience is a type of sam- 
pling in which the individuals selected are readily available to the researcher [28]. This type of sampling was chosen due to the limited time of the research process and due to the state of public health due to the covid-19 pandemic.

\subsection{Research Sample-Participants}

The participants in the proposed research will be active pre-school teachers, who will live or work in the Attica region and for the last ten years will have dealt with a child with mental retardation. Age criterion will not be used as long as teachers are in practice.

\subsection{Issues of Validity and Reliability}

The validity and reliability of research tools are crucial for the emergence of correct results in the research process. In case the validity of the research tools is not mentioned but also their reliability, it is not possible for the results of the research to be unreservedly taken into account regarding the validity of the results that will emerge.

A measuring instrument is valid when it actually measures what it claims to measure [29] and reliable when there is stability in successive measurements [30]. The validity of a tool is presumed when it is used many times successfully in a research-designed population. The terms "stability" and "internal coherence" that researchers must consider in order to use a measurement tool in practice, conceptually attribute reliability [30]. Minimizing accidental error when using a tool is associated with its high reliability. The minimization of random errors is achieved when the research tools are weighted and result from the literature (Pappas, 2002). A research tool is considered reliable when measurements under similar or similar conditions give similar or similar results respectively. The reliability and validity of the measuring instruments are important for ensuring correct results of a research [29]. In order to have a reliable factor analysis, as is desirable for the proposed research, we must obtain a sufficient sample size [28]. For example, at least 100 Preschool Teachers. In terms of the quantitative research methodological approach, the validity can be internal and external. More specifically regarding the internal validity of a research.

\subsection{Ethics Issues}

Ethics are key points of research, scientific, educational, social, etc. The issues that arise most often are the obtaining conscious consent of the participants in the research, the protection of personal data, the preservation and use of the results of the research after its completion (National Documentation Center, 2016).

An important element of any research is the preservation of the anonymity of the participants and the protection of personal data. To achieve this the researcher must assure the participants in the research that their personal information is confidential and for no reason can they disclose it. Confidentiality in 
research is ensured through a series of practices that ensure that the anonymity of participants is maintained. These practices are the deletion of characteristic, identifying details of the participants such as: name, address, contact details. The reporting of their general details such as year of birth instead of date, wider professional field instead of specialty. These techniques aim to preserve the research data and at the same time maintain the anonymity of the participants in it [31].

An additional key element of any research is to obtain informed consent which presupposes that all participants in the research should have been informed orally and in writing about the purpose of the research, the possible effects, the possibility of terminating their participation without any sanction, the maintenance the anonymity of the participants and the protection of personal data as well as the possibility of access to the research data. If the participants in the research belong to vulnerable social groups, they can participate in a research as long as there is a corresponding legal framework that provides for it. The consent must be written and signed (University of Crete, 2012).

In the context of the proposed research, confidentiality will be ensured by the fact that the presentation of the data will be done in a way that will not betray the identity of the participant [31]. Consent and up-to-date consent will be provided through the service of an information letter and an information form. Participants will be informed in writing about the purpose and process of the research, about the right to leave at any time they want and about the complete absence of risk from their participation in the research process. The details of the researcher will also be available, while maintaining anonymity and confidentiality will be highlighted. They are then asked to sign the consent form thus securing the consent and consent of the participants.

In the proposed research, there is no risk for the participants as long as it will be prepared in the context of an academic postgraduate thesis. The data collected will be encrypted and stored in a password folder known only to the researcher. In addition, all personal data collected from the questionnaires will be used solely for the purpose of conducting the survey and will not be disclosed to third parties without our prior consent.

\section{Research Questions}

The results of the present study will add new data to the scientific community and update data from findings from other research in the past. In particular, the research questions that the present research is called upon to answer through its final findings are the following.

What are the factors that affect the effectiveness of daily activities aimed at creating an inclusive climate in the preschool classroom?

What are the concerns of preschool teachers regarding inclusion?

$>$ What are the views of pre-school teachers on the conditions for applying for inclusion in pre-school education units?

What is the effect of demographic characteristics of preschool teachers? 
In the continuation of the present research follows a description and foundation of the theoretical background of the research where the basic theoretical concepts are analyzed. The bibliographic review of research and articles related to the research topic will be presented in detail. The methodological approach used for the present research, i.e. the quantitative approach, will then be extensively analyzed. The reasons chosen against the qualitative or other methodological approaches as well as the research tool and the techniques used for the data collection analyzed in the present research will be listed. In the same chapter, data and research interests of the research are assigned. The ethical issues and the ethics of the research process and how they were ensured in the given research are presented. In addition, the approach adopted for the analysis of the collected data is presented. The validity and reliability chapter and how they were achieved in the present study are also presented.

This is followed by the chapter on data analysis, which describes the findings and their significance, the researcher's personal concerns in relation to the findings and the analysis of the findings with the research and the theoretical framework analyzed in the literature review. At the end of the chapter are presented the limitations encountered during the research process. Finally, the chapter of conclusions follows, where a critical review of the research as a whole is made and the conclusions of the research process are presented, as well as some suggestions for improvement in the specific field.

\section{Data Analysis-Discussion}

The following is the presentation of the results of the questionnaires (95 out of 100 in total), as they emerged from the descriptive and inductive statistical analysis of the data using the statistical program SPSS (Statistical Package for Social Sciences).

\subsection{Descriptive Statistics Results-Demographics}

Initially, the analysis of the aggregate data as they emerged from the analysis of the questionnaires, begins with the presentation of demographics of the participants in the present survey through an aggregate table (Table 1).

Of the 95 preschool educators who participated in the present study, the majority were women with a percentage of $92.6 \%(f=88)$, while only $7.4 \%$ of the participants were men $(f=7)$. Regarding the age of the participants, $12.6 \%$ ( $f=$ $12)$ are under twenty-five years old, $30.5 \%(f=29)$ are twenty-six to thirty-five years old, 32.6\% $(\mathrm{f}=31)$ are thirty- six years old. forty-five years old, $23.2 \%(\mathrm{f}=$ 22) are forty-six to fifty-five years old, while the percentage of participants over fifty-six years old is infinitesimal with $1.1 \%(f=1)$. Regarding the existence or not of a person with Mental Disability in the family environment of the participants, the vast majority states that it does not exist with a percentage of $88.4 \%$ ( $\mathrm{f}$ $=84)$ while $11.6 \%(f=11)$ answer positively. Then, the vast majority of participants are general education teachers $71.6 \%(f=68)$ while special education 
Table 1. Aggregate demographics.

\begin{tabular}{cccc}
\hline Variables & Categories & Frequency (f) & Fig Frequency (f\%) \\
\hline \multirow{2}{*}{ Sex } & Woman & 88 & 92.6 \\
& Man & 7 & 7.4 \\
Age & $<25$ years old & 12 & 12.6 \\
& $26-35$ years old & 29 & 30.5 \\
& $36-45$ years old & 31 & 32.6 \\
& $46-55$ years old & 22 & 23.2 \\
Person with SE in the & $>56$ years old & 1 & 1.1 \\
family environment & Yes & 11 & 11.6 \\
& No & 84 & 88.4 \\
Specialty & General Education & 68 & 71.6 \\
& Teacher & & 28.4 \\
& EAE teacher & 27 & 7.4 \\
Years of service & $0-1$ year & 7 & 13.7 \\
& $2-3$ years & 13 & 15.8 \\
& $4-5$ years & 15 & 63.2 \\
6+ years & 60 & 45.3 \\
person with a SE & 0 - 1 year & 43 & 28.4 \\
& $2-3$ years & 27 & 20.0 \\
& $6+$ years & 19 & 6.3 \\
\hline
\end{tabular}

teachers constitute $28.4 \%$ of the total sample $(f=27)$. The percentage of participants with little work experience up to one year is at $7.4 \%(f=7)$. Immediately after are the educators with two to three years of service $13.7 \%(f=13)$, followed by educational experience of four to five years $15.8 \%(f=15)$ and finally the largest percentage of participants has work experience of more than six years with a rate of $63.2 \%(f=60)$. Of interest is the last question where participants are asked to note the years of work experience with a child with a mental disability. There the percentages are as follows. The highest percentage of $45.3 \%$ ( $f=$ 43) has no or up to one year of relevant previous service. Then $28.2 \%(f=27)$ report two to three years of corresponding work experience. $20.0 \%(f=19)$ report four to five years of service with a child with a mental disability, while only $6.3 \%(f=6)$ of the participants' report work experience with a child with mental retardation over six years.

\subsection{Results of Research Questions}

\subsubsection{Research Question 1}

Participants in the first part of the questionnaire are asked to answer based on a six-point scale whose rating is strongly disagree, disagree a little, disagree, agree a little, agree, strongly agree (Table 2 ). Regarding the integration practices in the first question with the average value being $4.82,31.6 \%$ completely agree that he can make clear to the students his expectations for their behavior, while $10.5 \%$ partially disagree $(\mathrm{t} . \mathrm{a}=0.942)$. To the second question about whether he is able 
Table 2. Cronbach's alpha credibility index for the "accession practices" dimension.

\begin{tabular}{|c|c|c|c|c|c|c|c|c|c|c|c|}
\hline $\begin{array}{l}\text { Accession } \\
\text { practices }\end{array}$ & $\begin{array}{l}\text { I absolutely } \\
\text { disagree }\end{array}$ & Disagree & $\begin{array}{l}\text { I disagree } \\
\text { a little }\end{array}$ & $\begin{array}{c}\text { I agree } \\
\text { a little }\end{array}$ & Agree & $\begin{array}{c}\text { Strongly } \\
\text { Agree }\end{array}$ & Skweness & kurtosis & $\begin{array}{c}\text { Average } \\
\text { Price (m) }\end{array}$ & $\begin{array}{l}\text { Standard } \\
\text { deviation }\end{array}$ & $\begin{array}{c}\text { Cronbach's } \\
\text { Alpha Rate } \\
\text { (a) }\end{array}$ \\
\hline Q1 & 0 & 0 & 10.5 & 29.5 & 28.4 & 31,6 & -0.283 & 1.053 & 4.82 & 1,000 & 0.942 \\
\hline Q2 & 0 & 0 & 4.2 & 43.2 & 18.9 & 33.7 & -0.567 & -0.303 & 5.06 & 0.836 & 0.941 \\
\hline Q3 & 0 & 1.1 & 3.2 & 47.4 & 11.6 & 36.8 & -1.105 & 1.745 & 5.16 & 0.829 & 0.940 \\
\hline Q4 & 0 & 2.1 & 4.2 & 51.6 & 14.7 & 27.4 & -1.080 & 1.664 & 4.98 & 0.887 & 0.938 \\
\hline Q5 & 0 & 0 & 5.3 & 34.7 & 28.7 & 31,6 & -0.297 & -0.896 & 4.93 & 0.902 & 0.939 \\
\hline Q6 & 0 & 2.1 & 3.2 & 42.1 & 24.2 & 28.4 & -0.756 & 0.699 & 4.92 & 0.919 & 0.939 \\
\hline Q7 & 1.1 & 1.1 & 5.3 & 27.4 & 43.2 & 22.1 & -0.414 & 0.812 & 4.61 & 0.992 & 0.940 \\
\hline Q8 & 0 & 0 & 5.3 & 40.0 & 27.4 & 27.4 & -0.290 & -0.711 & 4.89 & 0.869 & 0.939 \\
\hline Q9 & 0 & 4.2 & 10.5 & 36.8 & 36.8 & 11.6 & -0.415 & 0.066 & 4.41 & 0.973 & 0.941 \\
\hline Q10 & 1.1 & 5.3 & 11.6 & 32.6 & 29.5 & 20.0 & -0.588 & 0.020 & 4.47 & 1,156 & 0.944 \\
\hline Q11 & 0 & 0 & 2.1 & 43.6 & 22.1 & 29.5 & -0.332 & -0.546 & 5.03 & 0.778 & 0.939 \\
\hline Q12 & 0 & 1.1 & 1.1 & 27.4 & 16.8 & 53.7 & -1.167 & 1.113 & 5.32 & 0.866 & 0.941 \\
\hline Q13 & 0 & 0 & 3.2 & 27.4 & 14.7 & 54.7 & -1.034 & 0.107 & 5.34 & 0.846 & 0.942 \\
\hline Q14 & 0 & 1.1 & 3.2 & 50.5 & 17.9 & 27.4 & -0.812 & 1.109 & 5.00 & 0.825 & 0.941 \\
\hline Q15 & 0 & 1.1 & 7.4 & 48.4 & 17.9 & 25.3 & -0.757 & 0.407 & 4.89 & 0.905 & 0.940 \\
\hline Q16 & 1.1 & 7.4 & 9.5 & 34.7 & 29.5 & 17.9 & -0.660 & 0.69 & 4.43 & 1,173 & 0.941 \\
\hline Q17 & 0 & 1.1 & 6.3 & 33.7 & 28.4 & 30.5 & -0.449 & -0.425 & 4.86 & 0.963 & 0.940 \\
\hline Q18 & 0 & 0 & 1.1 & 38.9 & 17.9 & 42.1 & -0.548 & -0.671 & 5.22 & 0.774 & 0.940 \\
\hline
\end{tabular}

to calm down a student who makes a fuss, with an average value of 5.06, 33.7\% completely agree while $4.2 \%$ partially disagree ( $\alpha 0.941$ ). In addition to whether it can make parents feel comfortable coming to school, with an average value of $5.16,47.4 \%$ partially agree while $3.2 \%$ disagree a little (0.940). When asked if it can support families in how to help their children improve at school, with an average value of $4.98,51.1 \%$ partially agree while $4.2 \%$ disagree a little ( $\alpha$ 0.938). Regarding whether he can accurately assess what his students have understood from what he has taught, with an average value of $4.93,34.7 \%$ partially agree and $5.3 \%$ partially disagree ( $\alpha$ 0.939). $42.1 \%$ state that they partially agree that it can provide the appropriate learning challenges to very capable students, while $2.1 \%$ disagree a little ( $\alpha$ 0.939) with an average value of 4.92 . Whether they feel confident about their ability to prevent disturbing behavior before it occurs in the classroom, with an average of 4.61, 43.2\% agree while $1.1 \%$ strongly disagree ( $\alpha$ 0.940). Then in relation to whether they can control the annoying behavior in the classroom, with an average value of $4.8940 .0 \%$ partially agree while $5.3 \%$ partially disagree $(t . a=0.939)$. When asked if they feel confident in their ability to involve the parents of children with disabilities and/or special educational needs in their school activities, with an average value of $4.41,36.8 \%$ say they 
agree, also $36.8 \%$ state that they agree a little while $4.2 \%$ partially disagree (t.a $=$ 0.941). In addition to the confidence in preparing learning activities that meet the needs of children with disabilities and/or special educational needs, with an average value of $4.47,1.1 \%$ completely disagree while $32.6 \%$ partially agree (t.a $=$ 0.944). Regarding whether they are able to direct the children to follow the rules of the classroom, with an average value of $5.03,43.6 \%$ partially agree while $2.1 \%$ disagree a little $(\alpha$ 0.939). In relation to their ability to work with other professionals to design educational programs for students with disabilities and/or special educational needs, the average value is 5.32 with the vast majority of $53.7 \%$ completely agreeing while $1,1 \%$ disagree (t.a $=0.941)$.

At the same time, the majority of $54.7 \%$ state that they are able to work with other professionals and staff to teach students with disabilities and/or special educational needs in the classroom, with an average value of 5.34 while $3.2 \%$ partially disagree $(\mathrm{t} . \mathrm{a}=0.942)$. In the fourteenth question about their confidence in the ability to direct students to work in pairs or small groups, with an average value of $5.0050 .5 \%$ partially agree while $1.1 \%$ partially disagree ( $\alpha 0.941)$. In the next question about their ability to use various evaluation methods with an average value of $4.89,7.4 \%$ disagree a little while $34.7 \%$ partially agree (t.a $=0.940)$. Then on their ability to inform those who know little about the laws and policies regarding the inclusion of students with disabilities and/or special educational needs, the average value is 4.43 while $34.7 \%$ say they agree a little and $9.4 \%$ report disagree a little $(\mathrm{t} . \mathrm{a}=0.941)$. In question seventeen, $33.7 \%$ partially agree that they can deal with students who use physical violence, with an average value of 4.86 while $6.3 \%$ partially disagree ( $\alpha$ 0.940). Finally, regarding whether they can provide an alternative explanation or an example when students are confused with an average value of 5.22, $42.1 \%$ completely agree while $1.1 \%$ partially disagree (a 0.940).

\subsubsection{Research Question 2}

In the second part of the questionnaire teachers are asked to answer based on a four-point scale whose grading is strongly disagree, disagree, agree, strongly agree (Table 3). Regarding teachers' concerns about whether they are worried that students with intellectual disabilities will not be accepted by the other students in the class, the average value is 2.64 with $58.9 \%$ saying they agree while $21.1 \%$ that he completely disagrees $(\mathrm{t} . \mathrm{a}=0.829)$. Then in terms of whether they are worried that it will be difficult to give proper attention to all students in an inclusive class, the average value is at 2.71 with $60.0 \%$ agreeing while $15.8 \%$ strongly disagree $(\mathrm{t} . \mathrm{a}=0.793)$. Regarding whether they are worried that their workload will increase if they have students with intellectual disabilities in their class, with an average value of $2.20,33.7 \%$ agree while $30.5 \%$ disagree ( $\alpha$ 0.827). When asked if they are worried that they will be more anxious if they have students with intellectual disabilities in their classroom, with an average value of $2.58,50.5 \%$ note that they agree with $18.9 \%$ who disagree $(\alpha=0.764)$. Finally, regarding the concern that they lack the knowledge and skills required to teach 
students with intellectual disabilities, $48.4 \%$ agree while $20.0 \%$ disagree (ie 0.804 ) with the average value being 2.67 .

\subsubsection{Research Question 3rd}

Regarding the conditions for inclusion, the participants answered on the basis of a four-point scale, the rating of which was not at all, moderate, quite, excellent (Table 4). Their answers were as follows. In the First question about ensuring accessibility in space, the average price is 3.20 while $43.2 \%$ note that accessibility is extremely important compared to the $6.3 \%$ who note at all ( $\alpha 0.910)$. Regarding the organization of the space, the average price is 3.28 and $47.4 \%$ of the participants report it as extremely important while only 3.2 as not at all important (a 0.905). Then the average price is 3.42 and $58.9 \%$ typically state that the administrative support is extremely important in relation to the 2.1 which states it as not at all important ( $\alpha$ 0.912). $49.5 \%$ of the participants with the average price at 3.21 note as extremely important the support of KEDDY while $5.3 \%$ disagree stating it as not at all important (a 0.902). In addition, the majority of

Table 3. Cronbach's alpha reliability index for the "teacher concerns" dimension.

\begin{tabular}{ccccccccccc}
\hline $\begin{array}{c}\text { Teacher } \\
\text { Concerns }\end{array}$ & $\begin{array}{c}\text { I absolutely } \\
\text { disagree }\end{array}$ & Disagree & Agree & $\begin{array}{c}\text { Strongly } \\
\text { Agree }\end{array}$ & Skweness & kurtosis & $\begin{array}{c}\text { Average } \\
\text { Price (m) }\end{array}$ & $\begin{array}{c}\text { Standard } \\
\text { deviation }\end{array}$ & $\begin{array}{c}\text { Cronbach } \\
\text { Alpha Rate } \\
(\mathbf{a})\end{array}$ \\
\hline Q1 & 11.6 & 21.1 & 58.9 & 8.4 & -0.672 & 0.023 & 2.64 & 0.798 & 0.826 \\
Q2 & 12.6 & 15.8 & 60.0 & 11.6 & -0.733 & 0.066 & 2.71 & 0.836 & 0.739 \\
Q3 & 28.4 & 30.5 & 33.7 & 7.4 & 0.135 & -1.034 & 2.20 & 0.941 & 0.857 \\
Q4 & 17.9 & 18.9 & 50.5 & 12.6 & -0.439 & -0.693 & 2.58 & 0.929 & 0.764 \\
Q5 & 14.7 & 20.0 & 48.4 & 16.8 & -0.443 & -0.589 & 2.67 & 0.928 & 0.804 \\
\hline
\end{tabular}

Table 4. Cronbach's alpha reliability index for the "inclusion conditions" dimension.

\begin{tabular}{|c|c|c|c|c|c|c|c|c|c|}
\hline $\begin{array}{l}\text { Conditions } \\
\text { for } \\
\text { Integration }\end{array}$ & Not at all & Enough & Very & Excellent & Skweness & kurtosis & $\begin{array}{c}\text { Average } \\
\text { Price (m) }\end{array}$ & $\begin{array}{l}\text { Standard } \\
\text { deviation }\end{array}$ & $\begin{array}{c}\text { Cronbach } \\
\text { Alpha Rate } \\
\text { (a) }\end{array}$ \\
\hline Q1 & 6.3 & 10.5 & 40.0 & 43.2 & -0.997 & 0.423 & 3.20 & 0.870 & 0.910 \\
\hline Q2 & 3.2 & 12.6 & 36.8 & 47.4 & -0.938 & 0.268 & 3.28 & 0.808 & 0.905 \\
\hline Q3 & 2.1 & 12.6 & 26.3 & 58.9 & -1.171 & 0.473 & 3.42 & 0.793 & 0.912 \\
\hline Q4 & 5.3 & 17.9 & 27.4 & 49.5 & -0.852 & -0.357 & 3.21 & 0.921 & 0.902 \\
\hline Q5 & 12.6 & 20.0 & 25.3 & 42.1 & -0.581 & -0.975 & 2.97 & 1,066 & 0.902 \\
\hline Q6 & 7.4 & 10.5 & 13.7 & 68.4 & -1.497 & 0.949 & 3.43 & 0.953 & 0.904 \\
\hline Q7 & 4.2 & 7.4 & 22.1 & 66.3 & -1.671 & 2.122 & 3.51 & 0.810 & 0.911 \\
\hline Q8 & 2.6 & 14.7 & 18.9 & 53.1 & -0.886 & -0.653 & 3.14 & 1,088 & 0.899 \\
\hline Q9 & 4.2 & 9.5 & 37.9 & 48.4 & -1.104 & 0.769 & 3.31 & 0.813 & 0.905 \\
\hline Q10 & 6.3 & 14.7 & 30.5 & 48.4 & -0.935 & -0.88 & 3.21 & 0.921 & 0.902 \\
\hline
\end{tabular}


teachers $42.1 \%$ with an average value of 2.97 report support from special support staff as extremely important while 12.6 as not at all important ( $\alpha 0.902)$.

At the same time, the vast majority of teachers $68.3 \%$ state that the support of special education staff is extremely important, with an average value of 3.43 while 7.4 marks it as not at all important ( $\alpha$ 0.904). To the next question about whether the relationship of cooperation with the family environment is a prerequisite for integration, $66.3 \%$ of the participants answered exceptionally, with the average value being 3.51 and 4.2 answered at all $(\mathrm{t} . \mathrm{a}=0.911)$. Below in relation to whether the possibility of training in special education issues is a prerequisite for inclusion, the average price is 3.14 while $53.1 \%$ report that it is an exceptional degree in relation to the 2.6 that does not score at all $(\mathrm{t} . \mathrm{a}=0.8990)$. 48.4 mentions the creation of modified activities and tasks as an extremely important factor in contrast to the 4.2 which notes at all, with the average value at 3.31 (t.a $=0.905)$. Finally, for the creation of a personalized program, the average price is set at 3.21 with $48.4 \%$ answering exceptionally and 6.3 at all $(\mathrm{t} . \mathrm{a}=0.902)$.

\subsubsection{An Internal Consistency Reliability Analysis with Cronbach's alpha index}

To ensure the reliability of a survey (Reliability), it is necessary to verify that the results of the measurements reflect more accurately the amount of measurement. In addition, the reliability of the research characterizes the coherence of the questions and the correlations between them. According to Kouli [32] the validity of the research (Validity) describes the degree of adaptation of the measured concept. In the case where a measuring tool meets the validity criteria then it also meets those of reliability while the opposite should not be taken for granted.

For measurement of the reliability of the proposals of the questionnaire used scales the ratio (a) of formula Cronbach's Alpha, that estimates the reliability of internal consistency of a scale. It therefore calculates the internal coherence of the answers to grading scale questions [33]. According to Ouzounis \& Nakakis [29] the acceptable value of Cronbach's Alpha should be a $>0.7$. The higher the value of the Cronbach's Alpha coefficient, the more reliable the internal cohesion index is considered.

In the present study to check the reliability of his statements and the first part of the questionnaire, the internal consistency index Cronbach's Alpha (a) was evaluated for three parameters that emerged separately for each one, in order to determine how reliable each sub-scale is and how the questions that make them up are related to each other. The reliability indicator Cronbach's Alpha (a) for the parameter "Efficiency in creating an inclusive climate" is estimated as equal to 0.850 and very good, while for the parameter "Efficiency in the cooperation of the teacher with other professionals, teachers and parents" is estimated as equal to 0.862 and is also considered very good. Finally, for the parameter "Effectiveness in the management of classroom behaviors" it is estimated as equal to 0.876 and is also considered very good (Table 5: Cronbach's Alpha reliability index for the parameters of the dimension "Integration Practices"). 
Table 5. Cronbach's alpha reliability index for the "accession practices" dimension parameters.

\begin{tabular}{cc}
\hline Accession practices & Cronbach's Alpha Rate (a) \\
\hline $\begin{array}{c}\text { Effectiveness in creating an inclusive climate. } \\
\text { Effectiveness in the teacher's collaboration with other } \\
\text { professionals, teachers and parents. }\end{array}$ & 0.850 \\
Effectiveness in managing classroom behaviors. & 0.862 \\
\hline
\end{tabular}

\subsubsection{Research Question 4}

To answer the fourth research question, the various variables need to be studied in correlations through the demographic characteristics of the sample. At this point it is noted that the significance level is a $=0.05$.

Sex

To investigate differences in gender scales, the non-parametric Mann Whitney-U test was performed. According to the results (Table 6), no statistically significant difference was found between the two sexes, in terms of integration practices, teachers' concerns and conditions for integration.

\section{Person with SE in the family environment}

In order to investigate the existence of differences, in terms of the scales to the presence of a person with SE in the family environment, the non-parametric Mann Whitney-U test was performed here as well. According to the results of which no statistically significant difference was found between the participants who had a person with SE in their family environment and those who did not, in terms of the aforementioned scales (Table 7). Limit values are justified due to limited sample.

\section{Specialty}

The application of the non-parametric Mann Whitney-U test was continued to investigate the existence of differentiation in relation to the participants' specialty in terms of integration practices, teachers' concerns and conditions for inclusion (Table 8). Where also no statistically significant variation was observed and the limit values are justified due to a limited sample.

\section{Age}

In order to investigate the correlation between the three dimensions of integration practices, teachers' concerns and conditions of inclusion, the correlation in relation to age, the parametric control Anova was performed. According to the results, no statistically significant difference was found between the age groups, in terms of integration practices, teachers' concerns and conditions for integration, as we can see in the following Table 9 where totals came up the same for all the 3 dimensions.

\section{Work experience}

In order to investigate the existence of differences, in terms of scales in relation to work experience, the parametric control Anova was performed. At this point in the audit, a statistically significant difference was found between the 
Table 6. Gender correlation (Mann Whitney-U).

\begin{tabular}{ccccc}
\hline Scale & Men & Women & U & P. Value \\
\hline Accession Practices & 56.29 & 47.34 & 250,000 & 0.408 \\
Teacher Concerns & 41.07 & 48.55 & 259,000 & 0.487 \\
Conditions for Integration & 60.00 & 47.05 & 224,000 & 0.228 \\
\hline
\end{tabular}

Table 7. Correlation of the presence of a person with SE in the family environment (Mann Whitney-U).

\begin{tabular}{ccccc}
\hline Scale & $\begin{array}{c}\text { Yes/presence } \\
\text { of a person } \\
\text { with SE }\end{array}$ & $\begin{array}{c}\text { No/absence } \\
\text { of a person } \\
\text { with SE }\end{array}$ & U & P. Value \\
\hline Accession Practices & 62.68 & 46.08 & 300,500 & 0.060 \\
Teacher Concerns & 33.91 & 49.85 & 307,000 & 0.070 \\
Conditions for Integration & 54.95 & 47.09 & 385,500 & 0.090 \\
\hline
\end{tabular}

Table 8. Specialty correlation (Mann Whitney-U).

\begin{tabular}{ccccc}
\hline Scale & $\begin{array}{c}\text { General educa- } \\
\text { tion teacher }\end{array}$ & EAE teacher & U & P. Value \\
\hline Accession Practices & 44.82 & 56.00 & 702,000 & 0.074 \\
Teacher Concerns & 51.16 & 40.04 & 703,000 & 0.074 \\
Conditions for Integration & 46,46 & 51.98 & 813,000 & 0.156 \\
\hline
\end{tabular}

Table 9. Age correlation (Anova).

\begin{tabular}{|c|c|c|c|c|c|}
\hline & Sum of Squares & df & $\begin{array}{c}\text { Mean } \\
\text { Square }\end{array}$ & $\mathrm{F}$ & Sig. \\
\hline \multicolumn{6}{|l|}{ Integration Practices } \\
\hline Between Groups & 489,843 & 3 & & \multirow{3}{*}{1,166} & \multirow{3}{*}{0.327} \\
\hline Within Groups & 12745,694 & 91 & 163,281 & & \\
\hline Total & 13235,537 & 94 & 140,063 & & \\
\hline \multicolumn{6}{|l|}{ Concerns educational } \\
\hline \multicolumn{6}{|l|}{-Community Between } \\
\hline Groups & 77,038 & 3 & \multirow{3}{*}{$\begin{array}{l}25,679 \\
11,474\end{array}$} & \multirow{3}{*}{2,238} & \multirow{3}{*}{0.089} \\
\hline Within Groups & 1044,162 & 91 & & & \\
\hline Total & 1121,200 & 94 & & & \\
\hline \multicolumn{6}{|l|}{ Conditions for } \\
\hline \multicolumn{6}{|l|}{ Integration } \\
\hline Between Groups & 92,616 & 3 & 30,872 & \multirow{3}{*}{0.654} & \multirow{3}{*}{0.582} \\
\hline Within Groups & 4294,268 & 91 & 47,190 & & \\
\hline Total & 4386,884 & 94 & & & \\
\hline \multicolumn{6}{|l|}{ Total Sum } \\
\hline Between Groups & 663,965 & 3 & & \multirow{3}{*}{1,157} & \multirow{3}{*}{0.331} \\
\hline Within Groups & 17405,993 & 91 & 221,322 & & \\
\hline Total & 18069,958 & 94 & 191,275 & & \\
\hline
\end{tabular}


years of service, in terms of integration practices with sig. 0.023 while compared to the scales of teachers' concerns and conditions of integration, no differentiation is observed (Table 10).

\section{Work Experience with M.D}

To investigate the correlation between the three scales in relation to work experience with people with intellectual disabilities, the Anova parametric test was performed. According to the results (Table 11), a statistically significant difference was found between the years of service, in terms of inclusion practices, teachers' concerns and inclusion requirements with sig 0,002 for inclusion practices, sig 0.020 for educators' concerns and sig 0.000 for inclusion as well as for the total sum of the dimensions again the sig is 0.000 .

\section{Correlation of Total Subscales}

In order to check the correlation of the total sum of the subscales, the non-parametric Mann Whitney-U control and the Anova parametric control were used, where correlating the total sums results in a statistically significant difference in the work experience with a person with mental disability and disability (Table 12). Therefore, to do so, plenty of variables were used, such as the sex of the participant, the existence of SE in the family environment, the possible specialty that the participant may had, the age, the work experience as well as any previous service related to Mental Disorder.

\section{Discussion}

\subsection{Discussion of Findings - Research Questions}

Regarding the first research question, the teachers with their answers highlight a

Table 10. Correlation of work experience (Anova).

\begin{tabular}{|c|c|c|c|c|c|}
\hline & Sum of Squares & $\mathrm{df}$ & $\begin{array}{l}\text { Mean } \\
\text { Square }\end{array}$ & $\mathrm{F}$ & Sig. \\
\hline \multicolumn{6}{|l|}{ Integration Practices } \\
\hline \multicolumn{6}{|l|}{ Between Groups } \\
\hline Within Groups & 11921,799 & 91 & 437,912 & 3,343 & 0.023 \\
\hline Total & 13235,537 & 94 & 131,009 & & \\
\hline \multirow{2}{*}{\multicolumn{6}{|c|}{$\begin{array}{l}\text { Concerns educational- } \\
\text { Community Between }\end{array}$}} \\
\hline & & & & & \\
\hline Groups & 0.410 & 3 & \multirow{2}{*}{0.137} & \multirow{3}{*}{0.011} & \multirow{3}{*}{0.998} \\
\hline Within Groups & 1120,790 & 91 & & & \\
\hline Total & 1121,200 & 94 & 12,316 & & \\
\hline \multirow{2}{*}{\multicolumn{6}{|c|}{$\begin{array}{l}\text { Conditions for } \\
\text { Integration }\end{array}$}} \\
\hline & & & & & \\
\hline Between Groups & 70,862 & 3 & 23,621 & & \\
\hline Within Groups & 4316,022 & 91 & 47,429 & 0.498 & 0.685 \\
\hline Total & 4386,884 & 94 & & & \\
\hline \multicolumn{6}{|l|}{ Total Sum } \\
\hline Between Groups & 1266,623 & 3 & & & \multirow{3}{*}{0.084} \\
\hline Within Groups & 16803,335 & 91 & 422,208 & \multirow{2}{*}{2,287} & \\
\hline Total & 18069,958 & 94 & 184,652 & & \\
\hline
\end{tabular}


Table 11. Correlation of work experience with a person with SE (Anova).

\begin{tabular}{|c|c|c|c|c|c|}
\hline & Sum of Squares & $\mathrm{df}$ & $\begin{array}{l}\text { Mean } \\
\text { Square }\end{array}$ & $\mathrm{F}$ & Sig. \\
\hline \multicolumn{6}{|l|}{ Integration Practices } \\
\hline Between Groups & 1977,003 & 3 & & \multirow{3}{*}{5,327} & \multirow{3}{*}{0.002} \\
\hline Within Groups & 11258,534 & 91 & 659,001 & & \\
\hline Total & 13235,537 & 94 & 123,720 & & \\
\hline \multicolumn{6}{|l|}{ Concerns educational } \\
\hline \multicolumn{6}{|l|}{-Community Between } \\
\hline Groups & 114,575 & 3 & \multirow{3}{*}{$\begin{array}{l}38,192 \\
11,062\end{array}$} & \multirow{3}{*}{3,453} & \multirow{3}{*}{0.020} \\
\hline Within Groups & 1006,625 & 91 & & & \\
\hline Total & 1121,200 & 94 & & & \\
\hline \multirow{2}{*}{\multicolumn{6}{|c|}{$\begin{array}{l}\text { Conditions for } \\
\text { Integration }\end{array}$}} \\
\hline & & & & & \\
\hline Between Groups & 1521,351 & 3 & & \multirow{3}{*}{16,104} & \multirow{3}{*}{0.000} \\
\hline Within Groups & 2865,533 & 91 & 507,117 & & \\
\hline Total & 4386,884 & 94 & 31,489 & & \\
\hline \multicolumn{6}{|l|}{ Total Sum } \\
\hline Between Groups & 5074,836 & 3 & & & \\
\hline Within Groups & 12995,122 & 91 & 1691,612 & \multirow{2}{*}{11,846} & \multirow{2}{*}{0.000} \\
\hline Total & 18069,958 & 94 & 142,804 & & \\
\hline
\end{tabular}

Table 12. Correlation of Total Sums.

\begin{tabular}{|c|c|c|c|c|c|}
\hline Variable & Category & Mean Rank & $\mathrm{U}$ & anova & P.Value \\
\hline Sex & $\begin{array}{c}\text { Woman } \\
\text { Man }\end{array}$ & $\begin{array}{l}46.95 \\
61.21\end{array}$ & 215,000 & & 0.187 \\
\hline $\begin{array}{l}\text { Person with SE } \\
\text { in the family } \\
\text { environment }\end{array}$ & $\begin{array}{l}\text { Yes } \\
\text { No }\end{array}$ & $\begin{array}{l}61.23 \\
46.27\end{array}$ & 316,000 & & 0.90 \\
\hline Specialty & $\begin{array}{c}\text { General Education } \\
\text { Teacher } \\
\text { EAE teacher }\end{array}$ & $\begin{array}{l}45.47 \\
54.37\end{array}$ & 746,000 & & 0.156 \\
\hline Age & $\begin{array}{c}<25 \text { years old } \\
26-35 \text { years old } \\
36-45 \text { years old } \\
>46 \text { years old }\end{array}$ & $\begin{array}{l}35.75 \\
51.24 \\
49.19 \\
48.70\end{array}$ & & 0.331 & 0.416 \\
\hline $\begin{array}{l}\text { Work expe- } \\
\text { rience }\end{array}$ & $\begin{array}{l}0-1 \text { years } \\
2-3 \text { years } \\
4-5 \text { years } \\
6+\text { years }\end{array}$ & $\begin{array}{l}32.71 \\
42.38 \\
44.53 \\
47.00\end{array}$ & & 0.084 & 0.249 \\
\hline $\begin{array}{l}\text { Previous service } \\
\text { with M.D. }\end{array}$ & $\begin{array}{l}0-1 \text { years } \\
2-3 \text { years } \\
4-5 \text { years } \\
6+\text { years }\end{array}$ & $\begin{array}{l}33.70 \\
50.54 \\
69.24 \\
71.83\end{array}$ & & 0.000 & 0.000 \\
\hline
\end{tabular}

variety of factors that affect the effectiveness of daily activities in order to create an inclusive climate in the classroom. Specifically, they concern the skills of teachers. More specifically, one factor is the ability of each teacher to delimit and manage the behavior of his students. Either it defines clearly what behaviors he expects from them, or the control and management of some annoying behavior for example. Another factor is the ability to cooperate that governs the teacher 
both in terms of students' family environment, as well as interdisciplinary cooperation or collaboration with colleagues. An additional important factor is the ability and flexibility of the teacher during the learning process. If he can assess what his students have understood from what they have been taught, if he can give a variety of examples to make it easier for the student to understand what is being asked and if he can meet the requirements of both the weakest and most capable students. Teachers note that their ability to involve parents in the educational process but also to act supportively towards them in order to improve the student's school is a very important factor that affects the creation of an inclusive climate. Finally, the knowledge of the legislative and policy issues regarding the integration of students with disabilities and/or special educational needs is an additional factor that affects the creation of an inclusive climate in the classroom.

The second research question explores kindergarten teachers' concerns about integration. At this point teachers identify their concerns as follows. Primarily if a child with a Mental Disability will be accepted into the classroom by the other children. Then if the teachers themselves having a student with Mental Disability, they will be able to give equal attention to all children. A percentage of teachers note that they are concerned that their workload will increase significantly in this case. As their stress will increase as noted by the majority of respondents. In addition, a large portion of teachers are concerned that they lack the knowledge to properly train a person with a special educational need.

The conditions for inclusion concerning the third research question and their importance as shown by the results of the research, are as follows. Support for their work (administrative/KEDDY) is considered more important by teachers. Collaboration with other professionals, special support and training staff. Training in special education and training. Also important are the modified tasks and the personalized program where needed. Finally, it is noted that also important but to a lesser extent is the accessibility and organization of the space.

Finally, the fourth research question of the present research focuses on the effect of the demographic characteristics of preschool teachers on their views. The analysis that preceded both parametric and non-parametric controls shows that demographics regarding the gender, age, specialty and presence of a person with a Mental Disability in the family environment of the respondents do not show statistically any significant effect on integration practices. applied by teachers, to their concerns or to the conditions of inclusion [33]. What is obviously influential is first of all the general work experience of the teacher in relation to the integration practices he/she applies. Second and most important for the present study is that the work experience with a student with a Mental Disability has a corresponding effect on the integration practices, concerns and conditions of integration.

\subsection{Correlation of Findings}

From the findings of the present research on the views of teachers on integration 
practices for the inclusion of children with intellectual disabilities, confirms an earlier research finding [23] where the researcher presented the kindergarten as the most suitable "ground" for the implementation of integration practices. At the same time, previous findings of another research where the lack of cooperation between teachers was mentioned as a given, are in contradiction with the findings of the present where teachers consider it a very important integration practice and a necessary condition for integration. In addition, a finding from the same survey where teachers appear to be attached to the curriculum contrasts with a finding from the present study where in inclusion practices teachers report flexibility and personalization as tools. Finally, the findings of the present research, update them in the research of Tsiomi [26]. Specifically, In the present research the teachers note that they would have quite increased stress, if they had a child with special educational needs in their class in contrast to the previous research which states that they would not have much stress. Even the findings regarding the views of teachers on the implementation of integration practices coincide. Both in the previous findings and in the present research, the teachers apply the integration practices. In Tsiomi's research the teachers seem positive in the collaboration with colleagues while in the present research they consider it imperative. Consequently, the degree of importance of this condition has changed in recent years in terms of successful integration.

\section{Conclusions}

In summary, it is observed that a society that matures and has as its goal and purpose progress, can only reflect this trend both institutionally and politically. Consequently, it was expected but also imperative that the modern Greek legislation, amend and re-compose legislation with clear provisions for special education and training. The constant changes in perceptions about disability have, as expected, also affected the teaching industry. Considering that preschool children shape their character, it is understood that if a culture of mutual respect and acceptance is cultivated in the child at this tender age, then as an adult he will be much more trained, with empathy and social sensitivities. For these reasons it is of paramount importance to study the views of preschool teachers because they shape and educate children at this age which is so important for their later life.

Based on the above considerations, the topic of this research project was selected and the specific research questions were prepared. According to the further analysis, they were correctly designed, clearly and in direct correlation with the research tool, which is why they responded through this research.

\section{Suggestions and Restrictions}

In relation to the limitations of the research, initially the purpose was to provide one hundred questionnaires which will be analyzed. One hundred and seven questionnaires were finally administered, of which ninety-five were analyzed. 
Due to the public health situation due to the covid-19 pandemic, interpersonal contact with the participants was difficult to prohibit. Communication was therefore purely electronic. This event caused some difficulties for some participants where they left. An additional difficulty was the statistical analysis of the data collected through the Spss program since there was access for a limited time and this compressed the time frame for the writing of the present study. It had not yet been estimated that due to the pandemic and the social situation in which the country finds itself, several prospective participants were not in the mood to devote the necessary time to complete the questionnaire.

At this point it is considered good to record some suggestions for further investigation of the subject of this research. It is therefore proposed with the same research axes of the present study and using the same measuring tools on teachers' perceptions of the integration challenges faced by children with intellectual disabilities in their school integration, to collect an additional sample with similar characteristics from other areas of Greece in order to determine whether the data that emerged from the present study are similar to those that will emerge in other areas. Even if possible, it is proposed to conduct research on the same topic as the same research axes and tools, in a sample with similar demographic characteristics but on a larger scale, in more time and with a much larger sample. After the completion of the previous proposal, additional data could be added through a qualitative methodological approach and the use of a qualitative research tool (interview) so that the results are triangulated and there are more valid results.

\section{Acknowledgements}

This study would not have been possible without the contribution of numerous people. We would like to thank the educational staff who took part in the research.

\section{Conflicts of Interest}

The author declares no conflicts of interest.

\section{References}

[1] Soulis, S.G. (2013) Education and Disability. National Confederation of Persons with Disabilities, Athens, Self-Published.

[2] Antoniou, A.S., Geralexis, I. and Charitaki, G. (2017) Special Educators' Teaching Self-Efficacy Determination: A Quantitative Approach. Psychology, 8, 1642-1656. https://doi.org/10.4236/psych.2017.811108

[3] Dimitriadou, I. (2015) The Independent Living of People with Intellectual Disabilities: A Combined Study of the Views of Parents, Teaching Staff and Young People with Intellectual Disabilities in Greece. Doctoral Thesis, University of Macedonia, Thessaloniki. https://dspace.lib.uom.gr/bitstream/2159/17483/1/DimitriadouIoanna_PhD2015.pd $\underline{\mathrm{f}}$

[4] Polychronopoulou, S. (2003) Children and Adolescents with Special Needs and Ab- 
ilities: Modern Trends in Education and Special Support. Volume A, Atrapos, Athens.

[5] Kakouros, E. and Maniadaki, K. (2003) Child and Adolescent Psychopathology: A Developmental Approach. Typothito-George Dardanos, Athens.

[6] Schalock, R.L., Borthwick-Duffy, S.A., Bradley, V.J., Buntinx, W.H., Coulter, D.L., Craig, E.M. and Shogren, K.A. (2010) Intellectual Disability: Definition, Classification, and Systems of Supports. American Association on Intellectual and Developmental Disabilities, Silver Spring.

[7] The American Psychiatry Association (1994) Diagnostic and Statistical Manual of Mental Disorders. Fourth Edition, Washington DC.

[8] American Association in Intellectual and Developmental Disabilities (2021) Definition of Intellectual Disability. https://www.aaidd.org/intellectual-disability/definition

[9] Schalock, R.L., Shogren, K.A., Borthwick-Duffy, S.A., Bradley, V.J., Buntinx, W.H., Coulter, D.L., Craig, E.M., Gomez, S.H., Lacapelle, Y., Reeve, A., Snell, M., Spleat, A., Tasse, M., Thompson, M., Verdugo, Wehmeyer, Y. and Yeager, M. (2007) The Remaining of Mental Retardation. Understanding the Change to Intellectual Disability. Intellectual and Developmental Disabilities, 45, 116-124.

[10] Charitaki, G., Soulis, S.G. and Tyropoli, R. (2019) Academic Self-Regulation in Autism Spectrum Disorder: A Principal Components Analysis. International Journal of Disability, Development and Education, 68, 26-45. https://doi.org/10.1080/1034912X.2019.1640353

[11] Bania, F., Antoniou, A.S., Theodoritsi, M., Theodoritsi, I., Charitaki, G. and Billis, E. (2019) Interaction with Disabled Persons Scale (IDPS): Translation and Cross-Cultural Validation in Greek. Disability and Rehabilitation, 43, 988-995. https://doi.org/10.1080/09638288.2019.1643420

[12] Bania, F., Gianniki, M., Giannakoudi, S., Charitaki, G., Matzaroglou, C. and Billis, E. (2020) The Interaction with Disabled Persons Scale (IDPS): Evidencing Construct Validity with Factor Analysis and Measurement Invariance in Greek-Speaking Healthcare Students. Disability and Rehabilitation, 1-8. https://doi.org/10.1080/09638288.2020.1850890

[13] Tzivinikou, S., Charitaki, G. and Kagkara, D. (2020) Distance Education Attitudes (DEAS) during Covid-19 Crisis: Factor Structure, Reliability and Construct Validity of the Brief DEA Scale in Greek-Speaking SEND Teachers. Technology, Knowledge and Learning, 1-19. https://doi.org/10.1007/s10758-020-09483-1

[14] Stasinos, D. (2016) Special Education 2020 plus. Papazisi, Athens.

[15] Boyle, C.A., Decoufle, P. and Yeargin-Allsopp, M. (1994) Prevalence and Health Impact of Developmental Disabilities in US Children. Pediatrics, 93, 399-403.

[16] Soulis, S.G. (2002) Pedagogy of Integration: From the "School of Separation", to a "School for All”. Special Pedagogy 2. Volume 1, “Typothito" Publications, Athens.

[17] Hellas (2012) Ratification of the Convention on the Rights of Persons with Disabilities and the Optional Protocol to the Convention on the Rights of Persons with Disabilities. Law 4074/2012. National Printing Office, Athens.

[18] Zoniou-Sideris, A. (2011) The Disabled and Their Education. A Psychopedagogical Approach to Integration. "Pedio" Publications, Athens.

[19] Tzimas, G. (2007) 4th Panhellenic Conference on: "Equal School for Unequal Children", Athens, 4-6 May 2007.

[20] Klinger, J.K. and Vaughn, S. (2002) The Changing Roles and Responsibilities of an LD Specialist. Learning Disability Quarterly, 25, 19-31. 
https://doi.org/10.2307/1511188

[21] Zionou-Sideri, A. (1998) People with Disabilities and Their Education: A Psychopedagogical Approach to Integration. Greek Letters, Athens.

[22] Vlachou-Balafouti, A. (2012) Practical Implementation of Integration Programs for Children with Mental Retardation. In: Zoniou-Sideris, A., Ed., Act B: Contemporary Accession Approaches, Ellinika Grammata, Athens, 121-150.

[23] Anastasiou, D. (2005) Thoughts on the History of the Field of Learning Difficulties. Modern Education, 140, 155-172.

[24] Cohen, L. and Manion, L. (2000) Educational Research Methodology. Metaichmio, Athens.

[25] Sarafidou, G.O. (2011) Articulation of Quantitative and Qualitative Approaches: Empirical Research. 1st Issue, Gutenberg, Athens.

[26] Tsiomi, E. and Nanou, A. (2020) Cooperative Strategies for Children with Autism Spectrum Disorders in Inclusive Robotics Activities. Proceedings of the International Scientific Conference Society, Integration, Education, Vol. 4, 148-156. https://doi.org/10.17770/sie2020vol4.5147

[27] Mertens, D.M. (2009) Research and Evaluation in Education and Psychology. Metaichmio, Athens.

[28] Iseris, G. (2016) Statistical Methods of Checking the Validity and Reliability of Questionnaires. The Case of Greece. International Journal of Language, Translation and Intercultural Communication, 5, 175-189. https://doi.org/10.12681/ijltic.10665 https://www.researchgate.net/publication/309225596_Statistikes_methodoi_elencho u_enkyrotetas_kai_axiopistias_erotematologion_E_periptose_tou_CiGreece

[29] Cohen, L., Manion, L. and Morrison, K. (2008) Educational Research Methodology. Metaichmio, Athens.

[30] Ouzouni, Ch. and Nakakis, K. (2011) The Reliability and Validity of Measurement Tools in Quantitative Studies. Nursing, 50, 231-239.

[31] Charitakis, F. (2012) Reconstruction of Teaching Using ICT, Based on the Conceptual Framework of Technological and Pedagogical Knowledge of Content (ICT). Investigation of the Possibility in Teachers of Alexandroupolis. Diploma Thesis, Democritus University of Thrace, Xanthi. https://repo.lib.duth.gr/jspui/bitstream/123456789/1356/1/EA90.PDF

[32] Kouli, St. (2019) Capturing the Level of Didactic Self-Efficacy and Highlighting the Training Needs of Teachers Specializing in Mathematics. Diploma Thesis, School of Sciences and Technology, Postgraduate Studies in Mathematics, Hellenic Open University, Patra.

https://apothesis.eap.gr/bitstream/repo/44557/1/112800_\%ce\%9a\%ce\%9f\%ce\%a5\%c e\%9b\%ce\%97_\%ce\%a3\%ce\%a4\%ce\%91\%ce\%a5\%ce\%a1\%ce\%9f\%ce\%a5\%ce\%9b\%c e\%91.pdf

[33] Vogiatzi, X.A., Charitaki, G. and Kourkoutas, E. (2021) Assessing Psychometric Properties of the Sentiments, Attitudes and Concerns about Inclusive Education Scale in a Greek-Speaking Sample of In-service Teachers. Technology, Knowledge and Learning, 1-17. https://doi.org/10.1007/s10758-021-09554-x 